\title{
Schizophrenic Psychosis and Crime Prevention: An Intervention Project
}

\author{
Fernando Almeida ${ }^{1,2}$, Helena Moura ${ }^{3}$, Victor Mota ${ }^{3}$, Diana Moreira ${ }^{1,4^{*}}$ \\ ${ }^{1}$ Maia University Institute, Maia, Portugal \\ ${ }^{2}$ Abel Salazar Biomedical Sciences Institute, University of Porto, Porto, Portugal \\ ${ }^{3}$ Magalhães Lemos Hospital, Porto, Portugal \\ ${ }^{4}$ Faculty of Psychology and Educational Sciences, University of Porto, Porto, Portugal \\ Email:*dianapmoreira@gmail.com
}

How to cite this paper: Almeida, F., Moura, H., Mota, V., \& Moreira, D. (2016). Schizophrenic Psychosis and Crime Prevention: An Intervention Project. Advances in Applied Sociology, 6, 319-329.

http://dx.doi.org/10.4236/aasoci.2016.610024

Received: April 20, 2016

Accepted: September 25, 2016

Published: September 28, 2016

Copyright $\odot 2016$ by authors and Scientific Research Publishing Inc. This work is licensed under the Creative Commons Attribution International License (CC BY 4.0).

http://creativecommons.org/licenses/by/4.0/ (c) (i) Open Access

\begin{abstract}
The implementation of a clinical treatment project in any mental health service is critical. More than just thinking about clinical cases, it is essential to prevent the occurrence of decompensation in many of our patients. Individuals deemed Not Guilty by Reason of Insanity (NGRI) have often committed very serious crimes. The main goal is to investigate the monitoring and treatment of patients who suffer from a schizophrenic psychosis, specially. A total of 72 patients participated in the study. The participants were individuals deemed NGRI by the courts, under Article 20 of the Portuguese Criminal Code. Results demonstrated the unequivocally need to follow up decompensated patients after the court order extinguished and these individuals were free and responsible for their own paths. Literature shows that many of them recidivate and become dangerous. Suggestions are presented for a better framing and psychiatric follow-up. Thanks to the implementation of this project centered in outpatients' treatment, patients could be treated before its clinical decompensation would cause more serious criminal behavior than those perpetrated until that time. The importance of the implementation of this program is demonstrated by the clinical presentation of one case.
\end{abstract}

\section{Keywords}

Psychosis, Clinical Decompensation, Mental Health, Treatment

\section{Theoretical and Research Basis for Treatment}

The prevalence of violent behavior among the mentally ill has long been studied.

Wallace, Mullen, and Burgess (2004) conducted a study of the criminal convictions of schizophrenics, occurring over a period of 25 years, which was marked by a radical 
deinstitutionalization and by an increasing abuse of substances. For this study, they examined the criminal records of 2861 patients who were first admitted for schizophrenia in the Australian state of Victoria, in 1975, 1980, 1985, 1990 and 1995. Significantly higher rates of criminal convictions were found in schizophrenics with substance abuse compared to those who did not use substances (68.1\% vs. $11.7 \%$ ).

Almeida (2007) studied the criminal course of 33 schizophrenics (19 men, 14 women) between 1991 and 2003. They found that the patients had committed a total of 42 crimes, $74 \%$ against people and $24 \%$ against property, but only one of the crimes had been reported to authorities. This gives us the indication that the crimes committed by individuals with severe mental illness are often viewed with great tolerance and complacency. The negligent attitude of family and friends, not infrequently, contributes to the outbreak of a homicide.

Eriksson et al. (2011) carried out a prospective study of 35 years in a population of 377 schizophrenic patients and $25 \%$ of these subjects had criminal convictions against $6 \%$ of the non-schizophrenic subjects. The diagnosis of schizophrenia was associated with an almost triple risk of a conviction for a criminal offense (OR 2.787) and with a four-doubled risk of a conviction for a serious violent offense (OR 4.149). Fazel and Grann (2006), in a population of patients suffering from schizophrenia or non-schizophrenic psychosis, found a prevalence of violent behavior of $6.6 \%$, while Ran et al. (2010) found a prevalence of $10 \%$ in schizophrenic patients.

Millaud and Dubreucq (2005) mention that a history of threats and physical violence should be interpreted as a warning sign, especially if it has a tendency to intensify in the preceding months and weeks.

This aggressiveness might tend to blur in the first days following the hospitalization of acutely decompensated schizophrenics. The risk of homicide and violence among severely mentally ill individuals is not static, but rather dynamic. The intensification of psychosocial stress (e.g., poverty, living in a socially disadvantageous environment, living with individuals who are not able to understand their behavior or who react inappropriately to this behavior, divorce, unemployment, abandonment, rejection, economic difficulties, situations of conflict) and triggering factors like depressive symptoms and hopelessness, significantly potentiate homicidal behavior (Alves \& Almeida, 2011).

Elbogen and Johnson (2009) point out that being a victim of violence, divorce or separation, and unemployment, in the year before the action occurs, increases the risk of perpetrating violence by a factor of, respectively, 1.5, 2.0, and 1.6 (OR-odds ratio).

Becker et al. (2011) demonstrate that, of the approximately 13 million annual admissions to prisons in the United States of America (12.9\% of which are women), more than one million are individuals with Serious Mental Illness (SMI) (Becker et al., 2011). The authors studied a group of 3769 individuals who were detained in the prison of Pinelas County, in Florida, for at least one day between July 1, 2003, and June 30, 2004, in other words, about $10.4 \%$ of the individuals detained in that period of 12 months. The authors emphasized that the total absence of support from mental health services for many of the participants, or their very infrequent contact with mental health services, 
pointed towards failed opportunities to treat the patients, particularly those whose symptoms of mental illness led to crime and, thus, were subjected to reincarceration.

Falk et al. (2014) studied the distribution of convictions for violent crime in the Swedish population (1973-2004) and sought to identify risk factors for recidivism in violent crime. The authors included all the individuals born in 1958 - 1980 (2.393.765). Recidivist violent offenders (with a history of three or more convictions for violent crime) were compared to offenders convicted for one or two offenses, and to non-offenders. A total of 93,642 individuals (3.9\%) had at least one conviction for violent crime, 24,342 of whom were recidivist violent offenders (1.0\% of the population) and were responsible for $63.2 \%$ of the total convictions. Recidivist offending was associated with the male gender $(\mathrm{RO}=2.5)$, personality disorders $(\mathrm{RO}=2.3)$, conviction for violent crime before the age of $19(\mathrm{RO}=2.0)$, drug-related offenses $(\mathrm{RO}=1.9)$, non-violent crime $(\mathrm{RO}=1.9)$, substance abuse disorders $(\mathrm{RO}=1.9)$, and major mental disorders $(\mathrm{RO}=1.3)$.

Numerous other studies corroborate the previously explained ideas: the history of violence and consequent conviction are relatively common among the severely mentally ill, and the criminal history of a particular population is one of the best predictors of future crime (Correia \& Almeida, 2012). Incidentally, it is common for patients to relapse into crime after being released. In a systematic and meta-analysis of homicide recidivism and schizophrenia, the pooled estimate of the proportion of homicide offenders with schizophrenia who were homicide recidivists was $2.3 \%$ (Golenkov, Nielssen, \& Large, 2014). A study from Nilsson et al. (2011)—confirmed by other long-term follow-up studies on mentally disordered offenders and patients discharged from special hospitals (Friendship et al., 1999; Maden et al., 2004; Nilsson et al., 2011; Yoshikawa et al., 2007) - found that regardless of the length of follow-up period, only $20.0 \%$ of individuals were reconvicted for violent or violence-related crimes during the total followup period, resulting in a total reconviction rate of $27.0 \%$ when non-violent crimes were included.

Considering that individuals deemed NGRI by the courts often committed very serious crimes, the main aims of this clinical treatment were to ensure follow-up and appropriate therapeutic for these patients, to maintain all individuals in a care network and to prevent them to decompensate.

\subsection{Project "Psychiatric Monitoring of NGRI Outpatients" (Almeida et al., 2016)}

\subsubsection{Characterization}

Individuals declared NGRI by the courts often commit very serious criminality. It is absurd to keep these patients, after the security measure is declared extinct, without adequate supervision. Because many of these patients had absent or insufficient morbid consciousness, were fragile and had needy families, and were lack of a competent and careful supervision, they decompensated again after being placed on probation. Often, the relapse in alcohol and drugs use, as well as the abandonment of therapy, contributes to the decompensation of the disease sufferers. And repeated criminality, often severe, erupts again. 
Consequently, we have decided to implement the project "Psychiatric Monitoring of NGRI Outpatients" in Magalhães Lemos Hospital (HML) (Porto, north of Portugal), and focused on individuals who were declared NGRI by the courts, after completing the security measure and became free and owners of their lives.

Seventy-two participants, living within a $60 \mathrm{~km}$ from Porto, integrated the project.

The project was implemented between February 1, 2010 and January 31, 2012.

The team consisted of a psychiatrist, a psychologist, and a nurse.

This project aimed, generally, at ensuring follow-up and appropriate therapy for these patients, and specifically, at integrating and maintaining all individuals in a care network and preventing decompensation.

The study was conducted according to APA ethical standards.

\subsubsection{Objectives}

The overall goal was ensuring follow-up and appropriate therapy for these patients. The specific objectives consisted in integrate and maintain all individuals in a care network and prevent them from decompensating, preventing crime relapse:

1) Conducting the epidemiologic survey of the phenomenon, namely: identifying target individuals; identifying their places of residence; and getting to know the subject, his/her family and his/her residence;

2) Contacting other relevant providers in the subject's follow-up (general practitioner, social worker from the area of residence);

3) Visiting patients at home periodically, done by the nurse and/or psychologist;

4) Doing home consultation by the psychiatrist, when considered necessary by the members of the team;

5) Developing a patient report, updated regularly, covering clinical and psychiatric elements, including medical and nursing documentation, a social report, and other elements considered appropriate (e.g., evolution of the legal process).

\subsection{Method}

\section{Participants}

A survey was carried out at the Clinic for Psychiatry and Mental Health of Santa Cruz do Bispo (CPSMSCB) for all individuals who, from January 1, 2000 to September 30, 2010, were placed on probation.

The sample was composed of 72 participants (69 male; 52 single; $M$ age $=43.0 ; S D=$ 10.7, age 24 - 74; 30 were illiterate or did not complete primary education) residing within $60 \mathrm{~km}$ from the city of Porto.

Inclusion criteria comprise having Portuguese nationality, having been deemed NGRI between 2000 and 2010, and having fulfilled safety measures at the CPSMSCB. Participants who have a nationality other than Portuguese and participants who have fulfilled safety measures at the Sobral Cid Hospital or the Caxias Hospital were excluded. Diagnosis was made accordingly Diagnostic and Statistical Manual of Mental Disorders (DSM-IV-TR) (APA, 2002). 


\section{Case Introduction}

J., 42 years old, male, unmarried, six years of education is an example of the importance of the clinical outpatients treatment implemented. He is the youngest of five children. He used to work in construction and is not working since he was 29 years old. At 17 he started taking drugs (e.g., cannabis). However, only at 24 he showed behavioral changes that the parents associate with drugs.

\section{Presenting Complaints}

The first interview (on January 18, 2011) was conducted with the parents and a neighbor of the patient, because he was not at home. According to the patient's parents, there was evidence of psychotic phenomena. He was delusional, presented a loss of associative nexus, non-pragmatic, had no morbid consciousness, displayed severe behavioral modifications (which included aggressive behavior, walking down the street naked, etc.), lacked a sense of distance and convenience, and showed pronounced anger and hostility, particularly towards his parents and other family members, but also towards his neighbors. The parents were very skeptical regarding the possibility of the mental health service of the local hospital being able to treat their son. Among other reasons, because their son refused to attend the consultations at the mental health service of the local hospital, where, incidentally, he had been discharged due to abandoning the consultations-he had not attended the previously scheduled consultation.

On February 09, 2011, the patient was not at home when the whole team went there. He had left.

In the third visit, on February 25, 2011, the nurse and the psychologist visited the patient and could speak with him by the first time in the psychiatric hospital where he was hospitalized. The patient agreed to speak with the team. He was still angry because "I was angry because things have to be right ... when things are wrong, I get angry". He asked us if we attend church, continuing: "You think that is right? When the priest raises the host he knows it is made of esporrachim (derivative for sperm), dry shit and red shit ... why is he giving out the esporrachim, dry shit and red shit? They do things without anyone knowing, to foul people", including priests in this scam.

With an unwavering delusional conviction, he asserted, "I am in charge of the food. There is the one who rules the Earth, the one who commands the Fire and the one in charge of the Iron land ... they are five". His responsibility would be to evaluate what others eat "if it is dirty or clean", otherwise many people would die: "The last time I saw (people die) was because of snake venom, I saw them die in front of me, in prison, because of medication ... they took venom from the snake to kill the Portuguese...". His concern for the future of mankind was huge because he saw "the ozone be destroyed, I saw mankind be destroyed ... I saw the repair of the world ... they are playing with gravity and gravity is part of the ozone and you don't joke with it ... ozone is a part of the woman who keeps what was in the right place ... how could they be putting the woman's organs on men to get men pregnant? ... they kill women on the abortion boat 
to give organs to men?!".

As is easily understood from excerpts of the patient's interview, he was very decompensated about two weeks after being admitted, even though he was having the appropriate therapy. He was discharged properly compensated four weeks later.

\section{History}

With regard to his criminal history, we know that he served in prison a sentence of two years for crimes "theft and forgery of documents" between 1999 and 2001, the year he was released. Later, he completed another prison term between 2004 and 2009 after shoplifting at a supermarket with assault on a security guard, two offences of aggravated theft, coercion, and illegal possession of a firearm, and was sentenced to seven years, which began in March 2004.

He was diagnosed in the prison as a patient suffering from Schizophrenic Psychosis in the Paranoid Form (APA, 2002), and was medicated accordingly.

After being set free in 2009, he abandoned therapy, decompensating with a new psychotic break. He was admitted in a private psychiatric hospital for 15 days in the summer of 2010, but he ran away. Afterwards, he was referred to the consultations of the Psychiatry service of the local hospital, although, after attending the consultation, and because he missed the next one, he was discharged for abandoning the consultations. The family tried to activate a new compulsory detention with the prosecutor, without success. The result was that the patient remained untreated until the psychologist and the nurse of the team contacted the family on January $18^{\text {th }} 2011$, under our project of outpatient compulsory treatment of NGRI. The patient lived in a separate room (on the ground floor) of his parents' house, remodeled so that the patient is as independent as possible and not to disturb the parents, residing on the top floor of the dwelling. Fearful, the parents avoided contact with the patient, and reported being afraid of him and not even the fact that the patient made a lot of noise during the night ("radio set to maximum volume, hitting the walls, dragging the furniture, laughing out loud all alone, making threats...") and prevented them from sleeping, led them to stand up against their son. On the contrary, they did everything they could for that contact not to occur because their son had already been physically aggressive towards his parents, and continued to threaten them verbally. Even when they provided him with food, they did everything possible to make sure that there was no contact between them. The clinical evolution occurred in the wild state in which the patient was "left to himself", imprisoned in his own insanity.

When our team contacted the family, the parents told us that had he has episodes in which he "walks alone, talks loudly, his head is a mess ... he says that foreigners want to kill all the Portuguese and tells us to lock everything up". His father found him naked several times, namely, wandering down the street. A neighbor confirmed the behavioral changes of the patient, informed us that the patient is not doing well and that people are afraid of him "when he is like that, we even lock the doors".

A new contact for evaluation was scheduled for February 09, 2011, attended by the 
team's psychiatrist, raising the family's awareness to the importance of the patient's presence in his home.

On February 09, 2011, the team interviewed his parents and a brother, whose presence we had requested. They reported to us that the patient is increasingly suspicious, telling the mother that his father brings him "food and he doesn't want to eat it because he says the food is poisoned", further confirming that "At times, he doesn't know what he is doing, walks down the street without any clothes on ... speaks loudly, alone, at night he speaks and he only speaks nonsense". They have also reported an aggressive episode, which took place on February 06, 2011, in which the patient hurled stones at his parents' house, and they also described a situation where he assaulted his father after he came to the defense of his mother during a conflict situation caused by the patient.

Despite the absence of the patient, the team's psychiatrist conducted a psychiatric assessment report directed to the health authority, aiming at the patient's compulsory commitment $^{12}$. In addition, the psychiatrist called the health authority, to describe the situation and to inform the urgent need to intervene and refer the patient to an emergency department, for a very likely compulsory commitment, which happened on February $12,2011$.

Accessed by all the team at the Magalhães Lemos Hospital (HML), in Porto on June 30, 2011, he was well compensated with an excellent state of cleanliness and personal hygiene, well dressed and with looking good, with an entirely logical and coherent speech, without any change in perception, with morbid consciousness, puzzled by his past behaviors.

\section{Assessment}

J. was assessed using self-report measures and structured clinical interview: 1) socio-demographic data (name, date of birth, sex, marital status, birthplace, years of education, occupation, living arrangements, employment), 2) clinical data (psychiatric diagnoses, age of diagnosis, substance use, prior treatment, prior psychiatric admissions, history of head injury), 3) criminal history (age of first offence, prior convictions, previous convictions for violent offences), 4) offence data (date of offence, most serious offence, relationship to victim, number of victims, use of weapons), and progress through the forensic mental health system (dates of offences, date of apprehension, date of verdict, fitness for trial, dates of transfer between facilities, leave privileges granted, date of conditional release, readmission to psychiatric facilities).

After the individuals were identified, telephone contact was made with the patients' families to schedule an interview with both the patient and the family. If the patient was compensated, the team contacted the family after three months; if the patient was decompensated, the team tried his/her integration into a psychiatric care service; if the patient did not accept this intervention, the team made a second home visit, with the presence of the team's psychiatrist, who, when it was warranted, triggered the involuntary commitment of the patient. Exceptionally, and even if the local psychiatric service consulted the patient, the psychiatrist had the team treat the patient at HML. 


\section{Case Conceptualization}

The patient suffers from a schizophrenic psychosis which, if not properly treated, will tend to cause a new decompensation. In addition, the patient has a history of substance use, which tends to contribute to the decompensation of patients who suffer from schizophrenic psychosis.

The patient has a history of crime and prison records. The comorbid psychopathological condition from which he suffers cannot be overlooked - on the contrary - when addressing the problem of criminal recidivism.

Since patients who suffer from schizophrenic psychosis have greater potential to commit crimes when they decompensate, it is essential to treat them properly so they do not decompensate, nor fall back into crime.

Given the above, it is inconceivable that a patient suffering from schizophrenic psychosis and with a history of crime be left to himself, without adequate supervision from mental health services, when he is released from prison.

\section{Course of Treatment and Assessment of Progress}

The patient had a history in prison, suffered from a schizophrenic psychosis, and had left the psychiatric ward of the prison about two years ago.

J.'s family, due to exhaustion, feelings of inability and fear and unaware of the disease, was not a support for effective treatment of the patient. It was vital to explain to the family the disease, the symptoms and the treatment.

Living in the community, decompensated for over a year, without any treatment for about six months, everything indicated that the increasing criminality would end up in severe criminality.

The implementation of the project for the psychiatric monitoring of unaccountable outpatients has allowed rapid intervention and compensation for this patient, and the disruption of this criminal course.

Maintaining the patient under the care of the mental health services in his area of residence allows a closer supervision that is less costly for the patient.

Placing a patient such as J. in the community requires a schedule prior to the release of the subject to ensure an effective monitoring of the patient (unaccountable) to the consultation, with the transmission of relevant clinical and legal information and a more adequate monitoring of the patient's psychiatric treatment in the community. This work should be prepared when the subject is still completing the security measure.

For most patients, their families remained their foundation and fundamental support, even in situations when family members were the victims of the patient's criminal behavior (Lewis et al., 1998). When families, due to exhaustion or any other reason, are not an effective support for patients, particularly in the context of psychiatric treatment, the likelihood of decompensation and remaining decompensated for long periods of time is much higher (Almeida et al., 2012).

The promotion of independence and well-being of patients was a primordial objec- 
tive of this project contributing, also, to the maintenance of social peace, which requires timely monitoring and evaluation of the clinical status and functionality of the subject, through the articulation of and in network that allows the assessment and fostering of skills of the individual as a social being.

\section{Complicating Factors}

The fact that the patient was not being followed by the local mental health services and abandoned therapy after leaving the prison's psychiatric clinic was a crucial factor. Escaping the psychiatry service of the private hospital to which he was admitted in the summer of 2010 was another determining factor for the absence of treatment, as well as failing to compulsorily admit the patient when the family sought the magistrate of the Public Ministry. The disbelief of the parents regarding the effectiveness of the services were factors that contributed to the maintenance of the patient's situation and to the increase of criminal potential-the patient committed several crimes (e.g., threats, assaults, indecent exposure, civil disturbance), which, however, were not notified to the judicial or police authorities.

\section{Access and Barriers to Care}

The patient was not referred to a mental health service when he left the psychiatric clinic of the prison where he was detained.

After decompensating, he was admitted to a private hospital for psychiatric treatment. After fleeing the hospital, the family appealed to the Public Ministry, but the judicial authority did not activate the compulsory admission process. After resorting to the mental health service of the local hospital, and because he did not attend the consultations, he was discharged for abandoning the consultations.

The project for psychiatric outpatient treatment of patients considered not guilty by reason of insanity allowed to refer the patient, who was in a deplorable clinical situation, for proper treatment.

\section{Follow-Up}

The patient was consulted by the team on June 30, 2011 he was well compensated with an entirely logical and coherent speech, without any change in perception or in behavior. He was conducted to the psychiatric service of the area of the residence where the follow-up went on.

\section{Treatment Implications of the Case}

The findings clearly demonstrate the impact that the monitoring and the proper treatment of these patients is not always as effective as their pathology justifies it, and it unequivocally stresses that, if that strict monitoring is not conducted, the criminal relapse is inevitable and not negligible.

The results of this study underscore the success of programs designed to work with NGRI in the community. 


\section{Recommendations to Clinicians and Students}

The intervention with this patient was one of the most successful cases. A patient, such as J., suffering from a schizophrenic psychosis, with a history of substance use and criminal and prison records, should have never failed to be adequately monitored by health services. The criminal potential of a patient like J., with a varied and recurrent criminal record, should never be neglected. If our project had not been implemented, this patient would have continued to commit more crimes and, almost certainly, progressively severe crimes. Furthermore, the investment in this patient proved to be much more fruitful when the patient had a recovery with restitutio ad integrum, in other words, the heterologous symptomology or negative symptoms disappeared. Moreover, knowing that the more relapses into psychosis a patient has, and the longer he is ill, the less likely it is for him to have a restitutio ad integrum, therefore, it is very interesting that we achieved an excellent recovery of this patient. This clinical case helps explain a set of teachings: health services should be more effective and not take so long to refer these patients for treatment. When treated, many of these patients get incomparably better. This was the case with this patient, who was baffled by the behaviors he had perpetrated.

\section{Conflict of Interest}

The authors do not have any interests that might be interpreted as influencing the research. The study was conducted according to APA ethical standards.

\section{References}

Almeida, F. (2007). Crime and Schizophrenic Psychosis. Psiquiatria, Psicologia \& Justiça [Psychiatry, Psychology \& Justice], 1, 5-33.

Almeida, F., Moreira, D., Moura, H., \& Mota, V. (2016). Psychiatric Monitoring of Not Guilty by Reason of Insanity Outpatients. Journal of Forensic and Legal Medicine, 38, 58-63.

http://dx.doi.org/10.1016/j.jflm.2015.11.018

Almeida, F., Moreira, D., Silva, V., \& Cardoso, A. (2012). Internamento Compulsivo [Involuntary Commitment]. Psiquiatria, Psicologia \& Justiça [Psychiatry, Psychology \& Justice], 5, 49-66.

Alves, A., \& Almeida, F. (2011). Anomalia psíquica grave e criminalidade [Severe Mental Disorder and Crime]. Psiquiatria, Psicologia \& Justiça [Psychiatry, Psychology \& Justice], 4, 111-129.

American Psychiatric Association (APA) (2002). DSM-IV-TR: Manual de diagnóstico e estatística das perturbações mentais [Diagnostic and Statistical Manual of Mental Disorders]. Lisboa [Lisbon]: Climepsi Editores.

Becker, M., Andel, R., Boaz, T., \& Constantine R. (2011). Gender Differences and Risk of Arrest Among Offenders with Serious Mental Ilness. The Journal of Behavioral Health Services \& Research, 38, 16-28. http://dx.doi.org/10.1007/s11414-010-9217-8

Correia, D., \& Almeida, F. (2012). O internamento e o tratamento involuntários na União Europeia [Admission and Involuntary Treatment in the European Union]. Psiquiatria, Psicologia \& Justiça [Psychiatry, Psychology \& Justice], 5, 95-113.

Elbogen, E., \& Johnson, S. (2009). The Intricate Link between Violence and Mental Disorder: Results from the National Epidemiologic Survey on Alcohol and Related Conditions. Archives 
of General Psychiatry, 66, 152-161. http://dx.doi.org/10.1001/archgenpsychiatry.2008.537

Eriksson, A., Romelsjo, A., Stenbacka, M., \& Tengstrom, A. (2011). Early Risk Factors for Criminal Offending in Schizophrenia: A 35-Year Longitudinal Cohort Study. Social Psychiatry and Psychiatric Epidemiology, 46, 925-932. http://dx.doi.org/10.1007/s00127-010-0262-7

Falk, O., Wallinius, M., Lundstrom, S., Frisell, T., Anckarsater, H., \& Kerekes, N. (2014). The 1\% of the Population Accountable for $63 \%$ of All Violent Crime Convictions. Social Psychiatry and Psychiatric Epidemiology, 49, 559-571. http://dx.doi.org/10.1007/s00127-013-0783-y

Fazel, S., \& Grann, M. (2006). The Population Impact of Severe Mental Illness on Violent Crime. American Journal of Psychiatry, 163, 1397-1403. http://dx.doi.org/10.1176/ajp.2006.163.8.1397

Friendship, C., McClintock, T., Rutter, S., \& Maden, A. (1999). Re-Offending: Patients Discharged from a Regional Secure Unit. Criminal Behaviour Mental Health, 9, 226-236.

http://dx.doi.org/10.1002/cbm.315

Golenkov, A., Nielssen, O., \& Large, M. (2014). Systematic Review and Meta-Analysis of Homicide Recidivism and Schizophrenia. BMC Psychiatry, 14, 1-15.

http://dx.doi.org/10.1186/1471-244X-14-46

Lewis, M., Scott, D., Baranoski, M., Buchanan, J., \& Griffith, E. (1998). Prototypes of Intrafamily Homicide and Serious Assault among Insanity Acquittees. The Journal of the American Academy of Psychiatry and the Law, 26, 37-48.

Maden, A., Scott, F., Burnett, R., Lewis, G., \& Skapinakis, P. (2004). Offending in Psychiatric Patients after Discharge from Medium Secure Units: Prospective National Cohort Study. British Medical Journal, 328, 1534. http://dx.doi.org/10.1136/bmj.38075.467569.EE

Millaud, F., \& Dubreucq, J. (2005). Evaluation de la dangerosité du malade mental psychotique: Introduction. Annales Médico-psychologiques, revue psychiatrique, 163, 846-851. http://dx.doi.org/10.1016/j.amp.2005.09.009

Nilsson, T., Wallinius, M., Gustavson, C., Anckarsater, H., \& Kerekes, N. (2011). Violent Recidivism: A Long-Time Follow-Up Study of Mentally Disordered Offenders. PLoS ONE, 6, e25768. http://dx.doi.org/10.1371/journal.pone.0025768

Ran, M., Chen, P., Liao, Z., Chan, C., Chen, E., Tang, C. et al. (2010). Criminal Behavior among Persons with Schizophrenia in Rural China. Schizophrenia Research, 122, 213-218. http://dx.doi.org/10.1016/j.schres.2009.12.026

Wallace, C., Mullen, P., \& Burgess, P. (2004). Criminal Offending in Schizophrenia over a 25-Year Period Marked by Deinstitutionalization and Increasing Prevalence of Comorbid Substance Use Disorders. American Journal Psychiatry, 161, 716-727. http://dx.doi.org/10.1176/appi.ajp.161.4.716

Yoshikawa, K., Taylor, P., Yamagami, A., Okada, T., Ando, K., Taruya, T. et al. (2007). Violent Recidivism among Mentally Disordered Offenders in Japan. Criminal Behaviour Mental Health, 17, 137-151. http://dx.doi.org/10.1002/cbm.652 
Submit or recommend next manuscript to SCIRP and we will provide best service for you:

Accepting pre-submission inquiries through Email, Facebook, LinkedIn, Twitter, etc. A wide selection of journals (inclusive of 9 subjects, more than 200 journals)

Providing 24-hour high-quality service

User-friendly online submission system

Fair and swift peer-review system

Efficient typesetting and proofreading procedure

Display of the result of downloads and visits, as well as the number of cited articles

Maximum dissemination of your research work

Submit your manuscript at: http://papersubmission.scirp.org/

Or contact aasoci@scirp.org 